\title{
Giant honeybees (Apis dorsata) mob wasps away from the nest by directed visual patterns
}

\author{
Gerald Kastberger • Frank Weihmann • \\ Martina Zierler • Thomas Hötzl
}

Received: 28 April 2014 / Revised: 23 July 2014 / Accepted: 25 July 2014 / Published online: 29 August 2014

(C) The Author(s) 2014. This article is published with open access at Springerlink.com

\begin{abstract}
The open nesting behaviour of giant honeybees (Apis dorsata) accounts for the evolution of a series of defence strategies to protect the colonies from predation. In particular, the concerted action of shimmering behaviour is known to effectively confuse and repel predators. In shimmering, bees on the nest surface flip their abdomens in a highly coordinated manner to generate Mexican wave-like patterns. The paper documents a further-going capacity of this kind of collective defence: the visual patterns of shimmering waves align regarding their directional characteristics with the projected flight manoeuvres of the wasps when preying in front of the bees' nest. The honeybees take here advantage of a threefold asymmetry intrinsic to the prey-predator interaction: (a) the visual patterns of shimmering turn faster than the wasps on their flight path, (b) they "follow" the wasps more persistently (up to $100 \mathrm{~ms}$ ) than the wasps "follow" the shimmering patterns (up to $40 \mathrm{~ms}$ ) and (c) the shimmering patterns align with the wasps' flight in all directions at the same strength, whereas the wasps have some preference for horizontal correspondence. The findings give evidence that shimmering honeybees utilize directional alignment to enforce their repelling power against preying wasps. This phenomenon can be
\end{abstract}

Communicated by: Sven Thatje

Electronic supplementary material The online version of this article (doi:10.1007/s00114-014-1220-0) contains supplementary material, which is available to authorized users.

G. Kastberger $(\bowtie) \cdot$ F. Weihmann $•$ M. Zierler · T. Hötzl Department of Zoology, University Graz, Graz, Austria

e-mail: gerald.kastberger@uni-graz.at

F. Weihmann

e-mail: frank.weihmann@yahoo.de

M. Zierler

e-mail: martina.zierler@edu.uni-graz.at

T. Hötzl

e-mail: thohoe@aon.at identified as predator driving which is generally associated with mobbing behaviour (particularly known in selfish herds of vertebrate species), which is, until now, not reported in insects.

Keywords Giant honeybee $\cdot$ Apis dorsata $\cdot$ Shimmering · Defence waves $\cdot$ Repellence $\cdot$ Predatory wasp $\cdot$ Directional alignment

\section{Introduction}

Giant honeybees have evolved shimmering behaviour for collective defence (Seeley et al. 1982; Kastberger et al. 2011a; Weihmann et al. 2012). Visual threats provoke patterns reminiscent of Mexican waves, which propagate with a characteristic velocity and in a controlled direction over the surface of a giant honeybee nest (Kastberger et al. 2012, 2013a, b). The first 200-300 ms of a shimmering wave form a flash-like visual signal with the capacity to repel a preying wasp (Kastberger et al. 2008, 2010; cf. Tan et al. 2012). Depending on the distance from the nest and the velocity of the threatening wasp, the shimmering waves vary in the repetition rate and in the recruitment of nest mates. Lastly, a startle reflex is initiated in the preying wasp, which makes her turn around and fly away from the bees' nest (Kastberger et al. 2008).

However, shimmering is likely more sophisticated than just flashes of visual patterns which drive predatory wasps away from a giant honeybee colony (Kastberger et al. 2008, 2010; cf. Tan et al. 2012). On previous expeditions to India and Nepal (e.g. see the Movies in Kastberger et al. 2008, 2010), we suggested that the shimmering activities are tuned with the flight manoeuvres of the wasps in front of the bees' nest, in particular in the directedness of wave propagation and of the repeated performance. This observation also led to the assumption that giant honeybees drive predatory wasps out of 
the nest range by aligning their collective response with the wasp's flight. This directed-shimmering-drives-wasps hypothesis entails the control of rapidly changing external cues due to the flights of wasps on predation, based on a network of specialized bees on the nest surface (Schmelzer and Kastberger 2009) with the capacity to trigger hundreds of nest mates to align the spreading of their evoked visual patterns with the momentary direction of the wasp flight.

In this study, we show that shimmering behaviour does align, and even most of the time, with the flight of a wasp when preying in front of the bees' nest and thus visible for surface bees (Online Resource 5-14/Movies 1-10). We bring evidence that the driving party in the mutual alignment is the bees in defence rather than the wasps threatening the bee nest. These findings support the directed-shimmering-drives-wasps hypothesis that the sophisticated control of the virtual directedness of the shimmering patterns efficiently helps the honeybees to increase the repelling power of the shimmering flashes (Kastberger et al. 2008) to mob preying wasps out of the range of the bees' nest. Such kind of defence behaviour can be taken as a homologue to mobbing predators by selfish herds of vertebrate species (Hamilton 1971; Curio 1978; Arnold 2000; Alcock 2005; Chevalier 2013) but is, so far, unknown in the insect world.

\section{Material and methods}

Experimental site The experiments were conducted with Apis dorsata nests in the village of Sauraha, at the border of the Chitwan National Park, Nepal. Preliminary experiments had been carried out in 2003 (Kastberger et al. 2008) and in 2009 (Kastberger et al. 2011b, 2012, 2013a, b; Weihmann et al. 2012), but in November 2010 a single nest was selected for the much broader in-depth investigation described in this paper. This approximately 3-week-old nest was attached to a hotel balcony (Fig. S1/Online Resource 1; Kastberger et al. 2011b, 2012, 2013b; Waddoup 2014), it had a hemispherical form of $85 \times 60 \mathrm{~cm}$ (width $\times$ height) with a multi-layer cover comprising approximately 15,000 individuals.

Displacement of an experimental wasp nest The season of late November was selected for the experiments because at this time wasps are maximally abundant regarding colony size and numbers of nests. However, there was a paucity of freeflying wasps, even near giant honeybee nest aggregations, because Nepali farmers excessively exploit the wasp population due to their traditional use of wasp larvae as a supplementary protein source. They regularly burn the paper nests, barbecuing the wasp larvae and have thus reduced the population of wasps in Chitwan over a long period.

Therefore, the option of displacing wasp nests increased the chance for our experiments that single wasps approach the honeybee colony in its natural setting. We transferred a paper nest of Vespa tropica (individuals $>100$; brood cells $>100$ ) from $20 \mathrm{~km}$ away to the close vicinity of the experimental giant honeybee colony. After its relocation, the paper nest was encased with a curtain built of white and black linen. Utilizing the intrinsic positive phototaxis of forager wasps, we guided them through a tunnel of linen towards the experimental giant honeybee colony (Fig. S1/Online Resource 1) which they had to pass when departing or homing.

Experimental sessions, video recording and image processing The experimental giant honeybee nest was filmed (e.g. Movie 1/Online Resource 5) with high definition video (Panasonic HVX 200) at 50 frames per second (fps) with a resolution of $1,280 \times 720$ pixels (px). The camera was placed from slightly below at a distance of $1.5 \mathrm{~m}$ to capture the bees' nest (Figs. 1, S1/Online Resource 1) together with the wasps in front of it.

A film session of an interaction of preying wasps and shimmering honeybees started with the emergence of the wasp in the video image and ended with her disappearance (Movies 1-2/Online Resource 5-6). The sessions lasted $134.24 \pm 17.03$ frames corresponding to a footage duration of $2,684.80 \pm 357.63 \mathrm{~ms}\left(\mathrm{n}_{\mathrm{ss}}=50 ; \mathrm{fps}=50 \mathrm{~Hz}\right)$. The video films were formatted as jpg-sequences and processed by image analysis software (Image-Pro, Media Cybernetics) to detect wasp movements and shimmering activities of the honeybees. In total, 6,891 frames with wasps flying in front of the bees' nest were collected (compare the sample Movies 1-10/Online Resource $5-6$ comprising a single sequence over $179 \mathrm{ff} \equiv 2,540 \mathrm{~ms}$ documenting different stages of the evaluation process).

Assessment of shimmering movement Shimmering behaviour happens exclusively in the surface layer of the bee curtain of a giant honeybee nest. In the quiescent state, the individuals hang with their heads up und their abdomens down (Kastberger et al. 2011a), but during shimmering they flip their abdomens upwards by more than $90^{\circ}$ (Kastberger et al. 2011b) in a highly coordinated fashion which generates a Mexican wave-like process (Kastberger et al. 2012, 2013a, b).

Motion patterns of shimmering (sh) were detected by the differences in pixel luminance $\left(\operatorname{lum}_{\mathrm{px}}\right)$ in pairs of successive frames $\left(f_{i-1}, f_{i}\right)$ referred to the focus frame at the time $t_{i}(e . g$. Movies 3-7, 9-10). To eliminate single-pixel noise (Kastberger et al. 2012, 2013a, b), the resulting $\Delta$ lum $_{\mathrm{px}}$ values (with $\Delta \operatorname{lum}_{\mathrm{px}}\left[\mathrm{f}_{\mathrm{i}}\right]=\operatorname{lum}_{\mathrm{px}}\left[\mathrm{f}_{\mathrm{i}}\right]-\operatorname{lum}_{\mathrm{px}}\left[\mathrm{f}_{\mathrm{i}-1}\right]$; Fig. 1b) were filtered by eroding and dilating functions and segmented into two classes: in the first class, no or minor change in luminance values $\left(\Delta \operatorname{lum}_{\mathrm{px}} \leq 5\right)$ represented the "motionless" state; and in the second class, changes in luminance values of $\Delta \operatorname{lum}_{\mathrm{px}}>5$ signalled "movement". This movement coding was used to calculate the coordinates of the horizontal position 

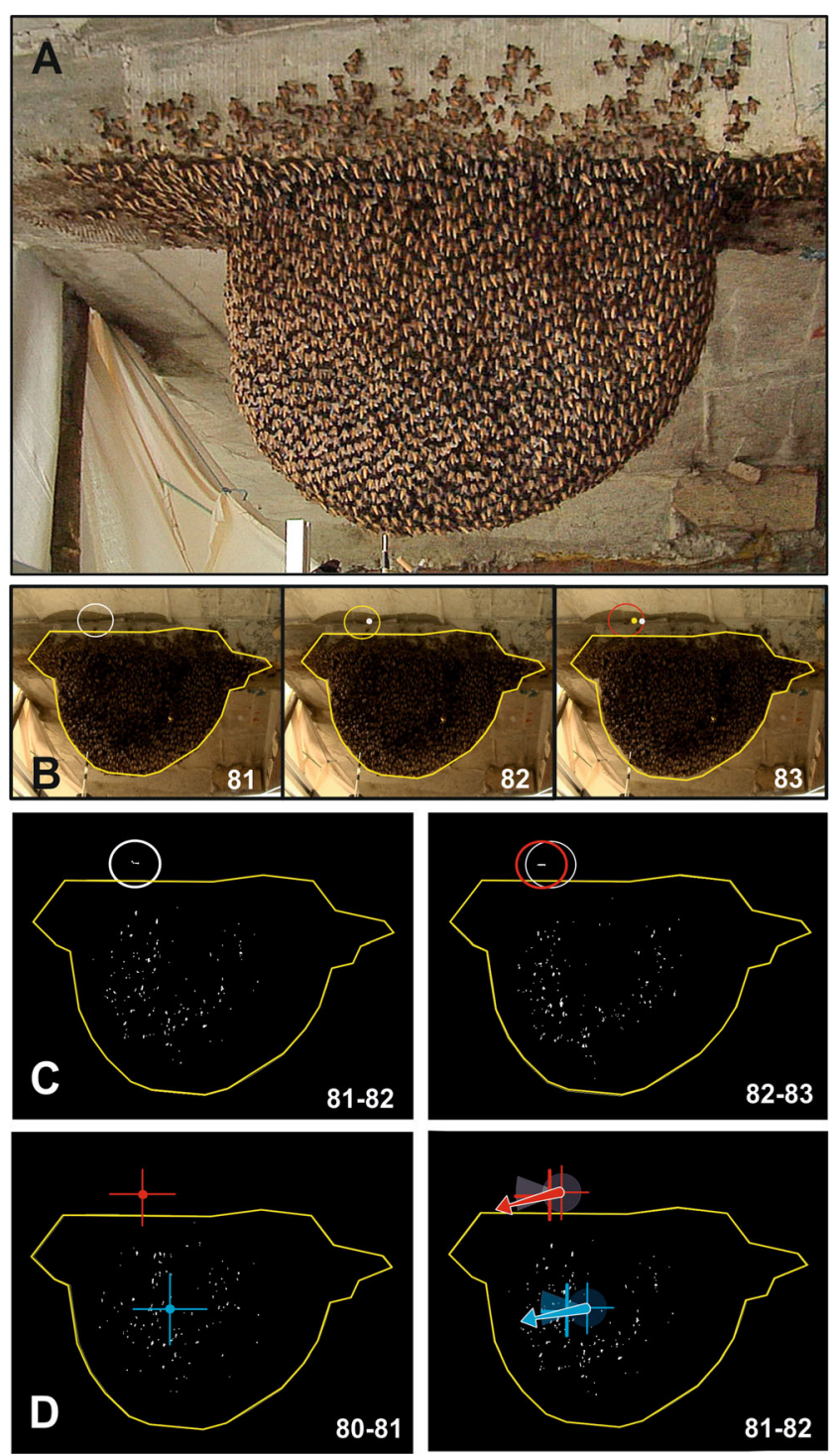

Fig. 1 Directional coincidence of the movements of shimmering bees and of the preying wasp. a Experimental giant honeybee nest in quiescent state. b Three frames (ff $81-83$; fps $=50 \mathrm{~Hz}$ ) document a wasp on prey flying just above the bees' nest and provoking shimmering waves; the wasp marked in the centre of the white circle (f 81 ) and in the centre of the yellow and red circles (ff 82,83 ) respectively; the white and yellow points mark the position of the wasp's thorax in respective frames before; yellow lines give the nest contours. $\mathbf{c}$ Differential images ( $\Delta$ ff 81-82, $\Delta$ ff 82-83) displaying segmented motions $(\Delta \mathrm{lum}>5)$ as white spots. Flight movement of the wasp was documented in the centre of the white circle ( $\Delta \mathrm{ff}$ 81-82) and of the red circle ( $\Delta \mathrm{ff} 82-83$ ), respectively. $\mathbf{d}$ The cross-points quantify the centres of the momentary motions of wasp (red) and shimmering (blue) as evaluated in the differential image $\Delta \mathrm{ff} 80-81$; in image $\Delta \mathrm{ff} 81-82$, the arrows give the movement vectors as the connections of the cross points at $\Delta \mathrm{ff} 80-81$ and $\Delta \mathrm{ff} 81-82$

$\left(\mathrm{x}_{\mathrm{sh}}\left[\mathrm{f}_{\mathrm{i}}\right]\right)$ and of the vertical position $\left(\mathrm{y}_{\mathrm{sh}}\left[\mathrm{f}_{\mathrm{i}}\right]\right)$ of the momentary gravity point of the shimmering wave at the time $t_{i}$ as explained in Eqs. 1a and 1b.

$x_{\mathrm{sh}}\left[\mathrm{f}_{\mathrm{i}}\right]=\Sigma \mathrm{x}_{\mathrm{m}} \mathrm{a}_{\mathrm{m}} / \Sigma \mathrm{a}_{\mathrm{m}}$
$\mathrm{y}_{\mathrm{sh}}\left[\mathrm{f}_{\mathrm{i}}\right]=\Sigma \mathrm{y}_{\mathrm{m}} \mathrm{a}_{\mathrm{m}} / \Sigma \mathrm{a}_{\mathrm{m}}$

whereas $\mathrm{m}_{\mathrm{px}}=1,2, . ., \mathrm{n}_{\mathrm{px}}$ gives the number of segmented pixel areas at the focus frame $f_{i}$, and $a_{m}$ gives the pixel size of the spot $\mathrm{m}_{\mathrm{px}}$.

Subsequently, the angular value $\left(\theta_{\mathrm{sh}}\right)$ of the direction of the shimmering wave was calculated (Eq. 2) on the basis of the positional changes of the gravity point (Eq. 1a and $1 \mathrm{~b}$ ) in the inter-frame interval $\Delta \mathrm{t}=\mathrm{t}\left[\mathrm{f}_{\mathrm{i}}\right]-\mathrm{t}\left[\mathrm{f}_{\mathrm{i}-1}\right]=20 \mathrm{~ms}$.

$$
\begin{aligned}
& \theta_{\text {sh }}=\arctan \left[\Delta \mathrm{x}_{\text {sh }} / \Delta \mathrm{y}_{\text {sh }}\right] \\
& \text { with } \Delta \mathrm{x}_{\text {sh }}=\mathrm{x}_{\text {sh }}\left[\mathrm{f}_{\mathrm{i}}\right]-\mathrm{x}_{\mathrm{sh}}\left[\mathrm{f}_{\mathrm{i}-1}\right] \\
& \text { and } \Delta \mathrm{y}_{\mathrm{sh}}=\mathrm{y}_{\text {sh }}\left[\mathrm{f}_{\mathrm{i}}\right]-\mathrm{y}_{\mathrm{sh}}\left[\mathrm{f}_{\mathrm{i}-1}\right]
\end{aligned}
$$

Assessment of the wasp movement The wasps (w) typically hovered and scanned at an average distance of $50 \mathrm{~cm}$ from the honeybee nest (Kastberger et al. 2008). For every frame $\left(\mathrm{f}_{\mathrm{i}}\right)$, the positions of head and abdominal tip were interactively determined by mouse clicks (Fig. 1; Movies 2-10/Online Resource 6-14) allowing to assess the coordinates of the wasp thorax (horizontal, $\mathrm{x}_{\mathrm{w}}$; vertical, $\mathrm{y}_{\mathrm{w}}$ ) as their topological projections even under weak contrast. The momentary projected direction of the flight path $\left(\theta_{\mathrm{w}}\right)$ at the time point $t\left[\mathrm{f}_{\mathrm{i}}\right]$ was calculated by determining the displacement of the thorax point of the wasp per frame interval (Eq. 3).

$$
\begin{aligned}
& \theta_{\mathrm{w}}=\arctan \left[\Delta \mathrm{x}_{\mathrm{w}} / \Delta \mathrm{y}_{\mathrm{w}}\right] \\
& \text { with } \Delta \mathrm{x}_{\mathrm{w}}=\mathrm{x}_{\mathrm{w}}\left[\mathrm{f}_{\mathrm{i}}\right]-\mathrm{x}_{\mathrm{w}}\left[\mathrm{f}_{\mathrm{i}-1}\right] \\
& \text { and } \Delta \mathrm{y}_{\mathrm{w}}=\mathrm{y}_{\mathrm{w}}\left[\mathrm{f}_{\mathrm{i}}\right]-\mathrm{y}_{\mathrm{w}}\left[\mathrm{f}_{\mathrm{i}-1}\right]
\end{aligned}
$$

Interaction of shimmering wave propagation and wasp flight Assessment of mutual signalling between wasps and shimmering bees. The behavioural context investigated here refers to the wasp as potential predator and to the shimmering bees as potential prey. In predator-prey interactions, signals are permanently produced by each of the parties eliciting responses in their counterparts. However, mutual signalling between wasps and shimmering bees happened at least in those time periods in which the wasps flew in front of the honeybees' nest with the heads directed towards it and in which a shimmering wave spread over the nest surface. The two behavioural aspects with signal value considered here were the moving patterns of the flight path of the wasps ( $w$; assessed as the positional changes of the wasp) and those of the shimmering waves ( $s h$; assessed as the positional changes of the gravity centre of shimmering).

The interaction between wasps and shimmering bees was categorized by the similarity between the time series of the counterparts ( $w$ and $s h$ ) as a function of a time lag applied to one or the other of them. This method considers both counterparts at every time point in two roles: (a) as the driving 
signaller, which provokes the other party's response, and (b) as the driven responder, which reacts to the signaller after a specific time lag. In the continuous sequence of interacting signals, the individual traits of both participants were separated by their roles as stimulating (driving) cue and as driven response to this cue by cross-correlating both time series ( $w$, $s h)$ using positive and negative time-lag filters. Therefore, cross-correlation of the two time series $(w, s h)$ delivers a measure for the level of interaction between initiating cue and driven response (abbreviated as cue $\rightarrow$ response), whereby the sign of the time lag determined the state as signaller or responder. Consequently, two aspects of interaction can be considered: (a) the course of the gravity centre of shimmering as response to the flight course of the threatening wasp, abbreviated further on as $w \rightarrow s h$ and (b) the wasp's flight course as response to the propagation direction of the shimmering wave $(s h \rightarrow w)$.

Angular quantification of the directional alignment For any time interval, the coincidence in movement direction of both traits $(w, s h)$ was classified as ipsi-directional (I), contradirectional (C) or intermediate (im). Proper ipsi-directional coincidence is given for any time point $t_{i}$ by equity of the angles $\left(\theta_{\mathrm{sh}}=\theta_{\mathrm{w}},\right)$ and proper contra-directional coincidence is given by opposite angles $\left(\theta_{\mathrm{sh}}=\theta_{\mathrm{w}}+180^{\circ}\right)$. For statistical purposes, we expanded this narrowly limited paradigm of coincidence by the range of $\Delta \theta_{\mathrm{A}}=45^{\circ}$ (Fig. S2A/Online Resource 2) to assign ipsi-directionality (abbreviated further as DIR $)$ with $\theta_{\mathrm{sh}}=\theta_{\mathrm{w}} \pm \Delta \theta_{\mathrm{A}}$ and contra-directionality $\left(\right.$ DIR $\left._{\mathrm{C}}\right)$ with $\theta_{\mathrm{sh}}=\theta_{\mathrm{w}}+180^{\circ} \pm \Delta \theta_{\mathrm{A}}$ (Fig. S2B/Online Resource 2). The missing intervals between ipsi- and contradirectionality are classed as intermediate alignment $\left(\mathrm{DIR}_{\mathrm{im}}\right.$ : $\left.\theta_{\text {sh }}=\theta_{\text {wasp }} \pm 90^{\circ} \pm \Delta \theta_{\mathrm{A}} / 2\right)$. For simplification, we categorized the alignment conditions $\left(\mathrm{DIR}_{\mathrm{I}}, \mathrm{DIR}_{\mathrm{C}}\right.$ and $\mathrm{DIR}_{\mathrm{im}}$; defined by Eqs. $4 \mathrm{a}, 4 \mathrm{~b}$ and $4 \mathrm{c}$ ) by eight angular sectors (cat $\theta=[1-$ 8]) comprising $360^{\circ}$ (see the sketches in Figs. 2, S2/Online Resource 2).

$\operatorname{DIR}_{\mathrm{I}}: \Delta$ cat $\theta_{[\mathrm{w}, \mathrm{sh}]} \equiv[+1]$ or $[0]$ or $[-1]$

$\operatorname{DIR}_{\mathrm{im}}: \Delta$ cat $\theta_{[\mathrm{w}, \mathrm{sh}]} \equiv[+2]$ or $[-2]$

$\operatorname{DIR}_{\mathrm{C}}: \Delta$ cat $\theta_{[\mathrm{w}, \mathrm{sh}]} \equiv[4]$ or $[+3]$ or $[-3]$

For the aspect of $w \rightarrow s h$, the difference in alignment is calculated by $\Delta$ cat $\theta(w \rightarrow s h)=$ cat $\theta_{[\mathrm{sh}]}-$ cat $\theta_{[\mathrm{w}]}$ and for the aspect of $s h \rightarrow w$ this difference is $\Delta$ cat $\theta(s h \rightarrow w)=$ cat $\theta_{[\mathrm{w}]}$ cat $\theta_{\text {[sh] }}$ (as exemplified in Fig. S2A/Online Resource 2).

Comparison of empirical data with a mathematical movement heading model Per definition, two parties are randomly aligned if both movements equal to a random walk (Einstein
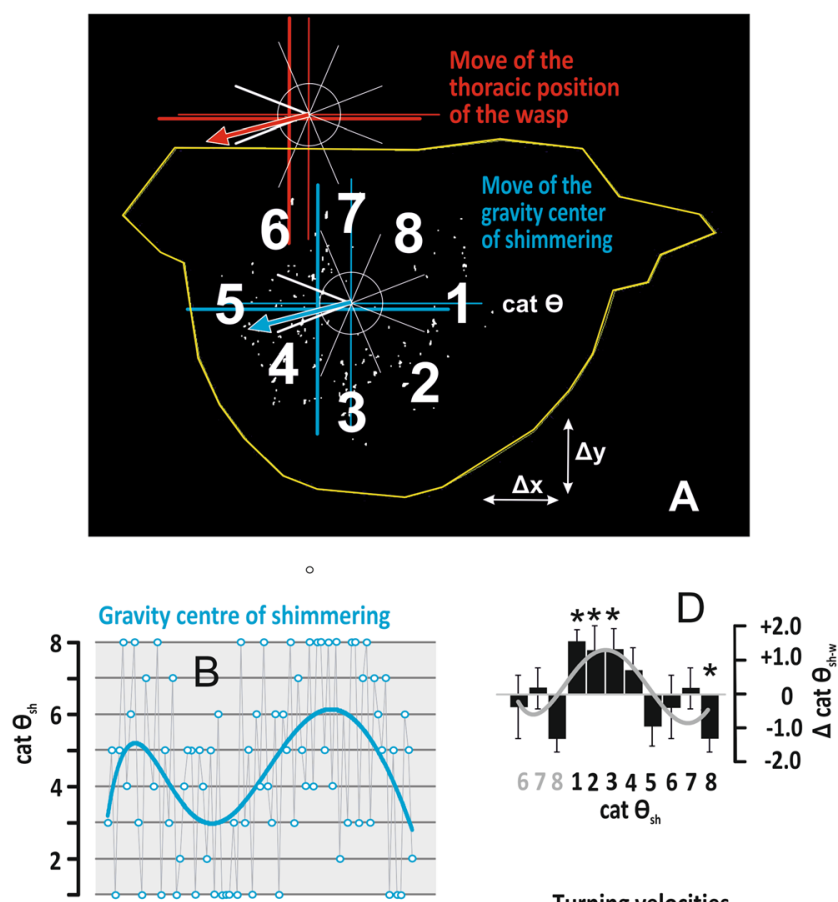

cat $\theta_{\text {sh }}$
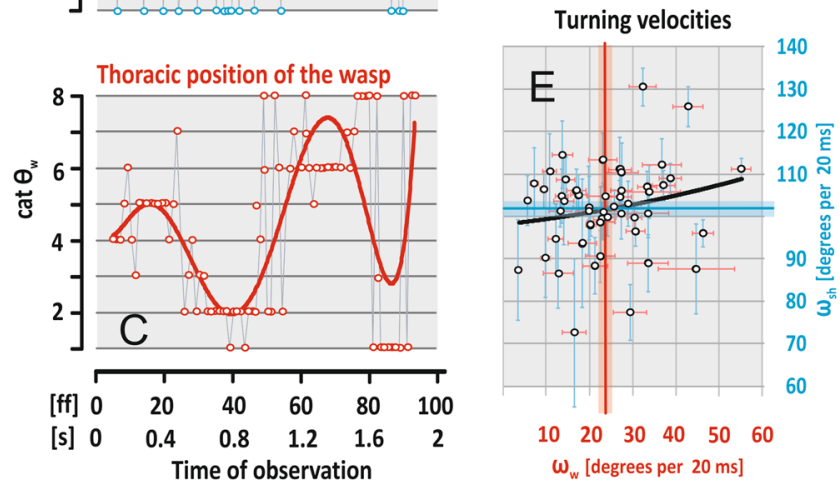

Fig. 2 Characteristics of directional interactions between wasp flight and shimmering. a The movements of wasp ( $w$ : red colour coding) and shimmering (sh: blue) assessed over three sequential inter-frame intervals: in this example, the wasp flew above the attachment zone of the honeybee nest (cf. Fig. S1/Online Resource 1) to the left side of the image (red arrow; as calculated by the change in position in three sequential frames, cf. Fig. 1). The shimmering wave also propagated to the left (blue arrow; calculated by the change in position of the gravity centre, see; cf. Fig. 1). White numbers give the eight angular sectors (cat $\theta=[1]-[8]$; cf. Fig. S2A/Online Resource 1) to classify the directions of $w$ - and sh-movements. b-c A single observation session with two wave episodes covering $1.6 \mathrm{~s}$ (abscissa; time in frames [ff] and seconds [s]); ordinates, movement angles categorized by the angular sectors of cat $\theta$ (for definition, see panel A and Methods); curves are regression functions (blue, cat $\theta_{\mathrm{sh}}$; $R^{2}=0.1877 ;$ red, cat $\left.\theta_{\mathrm{w}} ; R^{2}=0.4153\right)$. d Differences $\left(\Delta\right.$ cat $\theta_{\text {sh-w, }}$ black rectangles, means; vertical bars, SEMs) between the courses of the shimmering waves (panel B) and that of the wasp (panel C) plotted against the direction of shimmering (cat $\theta_{\mathrm{sh}}$ ); stars, significant deviations from zero ( $\mathrm{z}$ test; $\mathrm{n}_{\mathrm{ff}}=81$; grey curve, regression of the mean differences: $\left.R^{2}=0.5408\right)$. e Relation between turning velocities ( $\left(\right.$ abscissa, $\omega_{\mathrm{w}}=\Delta \theta_{\mathrm{w}} / \Delta \mathrm{t}$; ordinate, $\omega_{\mathrm{sh}}$ in degrees per $20 \mathrm{~ms} ; \mathrm{n}_{\mathrm{ss}}=$ 50 sessions; $\mathrm{n}_{\mathrm{ff}}=6,200$ inter-frame intervals); means (black open circles) and SEMs (coloured thin lines) of the values of each of the sessions; coloured triple lines throughout the panel, overall means and SEMs; black line, linear regression function of mean values $\left(R^{2}=0.0422\right)$ 
1926), the mathematical formalization of a path that consists of a succession of random steps. Movements which differ from random walk are supposed to arise from reactions, intentions or decisions. The split-component method was used to detect coincidence in the directionality of the time series $w$ and $s h$ for the movement components ( $\Delta \mathrm{x}$ and $\Delta \mathrm{y}$ ) per interframe interval. Two modes of alignment can be distinguished: (a) ipsi-directionality (abbreviated as $\mathrm{x}_{\mathrm{I}}$ or $\mathrm{y}_{\mathrm{I}}$ ), if the movement components of both counterparts $\left(\Delta \mathrm{x}_{\mathrm{w}}, \Delta \mathrm{x}_{\mathrm{sh}}\right.$ and $\Delta \mathrm{y}_{\mathrm{w}}$, $\Delta \mathrm{y}_{\mathrm{sh}}$ ) changed within a single inter-frame interval with the same sign (e.g. referring to the horizontal components: $\left[\Delta \mathrm{x}_{\mathrm{sh}}>0, \Delta \mathrm{x}_{\mathrm{w}}>0\right]$ or $\left.\left[\Delta \mathrm{x}_{\mathrm{sh}} \leq 0, \Delta \mathrm{x}_{\mathrm{w}} \leq 0\right]\right)$. (b) Contradirectionality (abbreviated as $\mathrm{x}_{\mathrm{C}}$ or $\mathrm{y}_{\mathrm{C}}$ ), if the movement components differed in their signs (e.g. referring to the horizontal component: $\left[\Delta \mathrm{x}_{\mathrm{sh}}>0, \Delta \mathrm{x}_{\mathrm{w}} \leq 0\right]$ or $\left.\left[\Delta \mathrm{x}_{\mathrm{sh}} \leq 0, \Delta \mathrm{x}_{\mathrm{w}}>0\right]\right)$. Each step of interaction represents one pair of alignment defined by the movement steps of both counterparts $\left(\left[\Delta \mathrm{x}_{\mathrm{sh}}\right.\right.$, $\left.\Delta \mathrm{y}_{\mathrm{sh}}\right]$ and $\left.\left[\Delta \mathrm{x}_{\mathrm{w}}, \Delta \mathrm{y}_{\mathrm{w}}\right]\right)$. This allows distinguishing ipsidirectional $\left(\left[\mathrm{x}_{\mathrm{I}}, \mathrm{y}_{\mathrm{I}}\right]\right.$, abbreviated further on as $\left.\mathrm{DIR}_{1}\right)$, two intermediate alignment conditions $\left(\left[\mathrm{x}_{\mathrm{C}}, \mathrm{y}_{\mathrm{I}}\right]\right.$ : $\mathrm{DIR}_{2} ;\left[\mathrm{x}_{\mathrm{I}}, \mathrm{y}_{\mathrm{C}}\right]$ : $\left.\mathrm{DIR}_{3}\right)$ and contra-directional $\left(\left[\mathrm{x}_{\mathrm{C}}, \mathrm{y}_{\mathrm{C}}\right]\right.$ : $\left.\mathrm{DIR}_{4}\right)$.

In this paper, we introduce a mathematical movement heading model which uses this split-component method on the basis of a doubly randomized algorithm (with $0.00 \leq$ rnd $(\mathrm{q}) \leq 1.00)$ to separately assign value $\left(=\mathrm{q}_{\text {value }}\right)$ and $\operatorname{sign}\left(=\mathrm{q}_{\text {sign }}\right)$ of each of the directional components for every step of movement of both parties in interaction. A path of movement can be described by its heading factor $h$ which refers to the statistical difference of the probabilities $(\mathrm{P})$ between positive directions $(\Delta x>0$, directed to the right in the image; $\Delta y>0$, directed to the top in the image) and negative directions $(\Delta x<0, \Delta y<0)$ over time according to Eqs. $5 \mathrm{a}$ and $5 \mathrm{~b}$.

$\mathrm{h}_{\mathrm{x}}=\mathrm{P}(\Delta \mathrm{x}>0)-\mathrm{P}(\Delta \mathrm{x}<0)$

$\mathrm{h}_{\mathrm{y}}=\mathrm{P}(\Delta \mathrm{y}>0)-\mathrm{P}(\Delta \mathrm{y}<0)$

Given the position of both parties $\left(\mathrm{x}_{0}\right.$ and $\left.\mathrm{y}_{0}\right)$ at the time $\mathrm{t}_{0}$ and the heading factors for both directional components, the value of the subsequent movement step was defined by $\Delta x=\operatorname{rnd}\left[\Delta \mathrm{x}_{\text {value }}\right]$ and $\Delta y=r n d\left[y_{\text {value }}\right.$. Its sign was determined by initializing functions ( $\operatorname{sign}[\Delta \mathrm{x}]=\operatorname{rnd}\left[\Delta \mathrm{x}_{\text {sign }}\right]$; $\left.\operatorname{sign}[\Delta \mathrm{y}]=\operatorname{rnd}\left[\Delta \mathrm{y}_{\text {sign }}\right]\right)$ and a threshold algorithm regarding the time interval $\left(\Delta \mathrm{t}=\mathrm{t}_{\mathrm{i}}-\mathrm{t}_{0}\right)$ which defines the sign of both directional components $(\Delta \mathrm{c}$ as $\Delta \mathrm{x}$ or $\Delta \mathrm{y}$ ) as positive for rnd $\left[\Delta \mathrm{c}_{\text {sign }}\right]<\mathrm{h}_{\mathrm{c}}$ and negative for rnd $\left[\Delta \mathrm{c}_{\text {sign }}\right]>\mathrm{h}_{\mathrm{c}}$. In the model, the theoretical position of both parties at the time point $t_{i}$ was calculated by integration of the $x$ - and $y$ components according to Eq. 6a and Eq. 6 b.

$$
\begin{aligned}
& \mathrm{x}_{\mathrm{i}}=\mathrm{x}_{0}+\operatorname{sign}\left(\operatorname{rnd}\left[\Delta \mathrm{x}_{\text {sign }}\right]\right) * \operatorname{rnd}\left[\Delta \mathrm{x}_{\text {value }}\right] \\
& \mathrm{y}_{\mathrm{i}}=\mathrm{y}_{0}+\operatorname{sign}\left(\operatorname{rnd}\left[\Delta \mathrm{y}_{\text {sign }}\right]\right) * \operatorname{rnd}\left[\Delta \mathrm{y}_{\text {value }}\right]
\end{aligned}
$$

For explanation, the heading factors $\mathrm{h}_{\mathrm{x}}$ and $\mathrm{h}_{\mathrm{y}}$ are zero under random walk condition, but bigger heading values will result in walking paths as displayed in Fig. S3A/Online Resource 3. For instance, a heading factor of $h_{x}=+0.50$ means that the horizontal movement component $(\Delta \mathrm{x})$ was positive in $75 \%$ of the cases (represented here by the time steps $\Delta t$ ) and it was negative in the complement of $25 \%$ of cases.

Directional alignment of two walking parties can be described by the momentary values of their headings. Random alignment is given if the headings of each of them are zero $\left(\mathrm{h}_{\mathrm{x}}[w]=\mathrm{h}_{\mathrm{x}}[s h]=\mathrm{h}_{\mathrm{y}}[w]=\mathrm{h}_{\mathrm{y}}[s h]=0\right)$. In terms of the normalized distributions of alignment, these random walk conditions result in uniform rates of the alignment components ( $\mathrm{r}$ $\left.\left[D_{R} R_{1-4}\right]=0.25\right)$. Variation of the heading factors of the two parties, reflected in the probability histograms in Fig. S3B/ Online Resource 3, can be extended into the lookup table as displayed in Fig. S3C/Online Resource 3.

\section{Results}

Directional alignment of shimmering waves with the flight paths of preying wasps When wasps prey in front of a giant honeybee nest, they provoke shimmering waves (Kastberger et al. 2008). Thus, both counterparts ( $w$ and $s h$ ) display moving patterns which happen, topologically seen, on roughly parallel vertical planes (Fig. 1): the shimmering waves propagate over the nest surface layer and the preying wasps fly at an average distance of $50 \mathrm{~cm}$ (Kastberger et al. 2008) from the nest surface. The frame-wise analysis of the projected movement angles of both parties $\left(\theta_{\mathrm{w}}, \theta_{\mathrm{sh}}\right.$; see Figs. 2a, S2A/Online Resource 2) demonstrates strong coupling of both directional vectors. A joint course can be documented even for a single session of interaction, illustrated by the regression functions (Fig. 2b-c) and confirmed by the distribution of the differential angles ( $\Delta$ cat $\theta_{\mathrm{w}-\mathrm{sh}}$ in Fig. $2 \mathrm{~d}$ ). Both movements differed weakly $\left(-45^{\circ} \geq \Delta\right.$ cat $\left.\theta_{\text {sh-w }} \geq+45^{\circ}\right)$ and only in four from eight angular cat $\theta_{\mathrm{sh}}$ sectors $[1-3,8]$.

This correspondence in the movements of wasp and shimmering is further illustrated in the film episode (Movies 1-10) in which the first shimmering wave was elicited when the wasp came into the visual range of the honeybee colony. Then, the wasp flew from the left side to the mid of the image near the lower nest rim while the shimmering wave propagated from here in up-right direction (which is roughly parallel to the wasp flight path). Possibly intimidated by the wave (Kastberger et al. 2008), the wasp responded by flying downwards and subsequently by turning around to fly back to the left side of the image and leaving the nest range. During this flight manoeuvre, a further shimmering wave was elicited which again propagated roughly in the same direction as the wasp path (from the lower rim to the up-left nest side). 
In total, the two counterparts differed significantly in their turning velocities $(\omega=\Delta \theta / \Delta t)$. The wasp produced turning velocities of $\omega_{\mathrm{w}}=23.87 \pm 1.57$ [degrees per $20 \mathrm{~ms}$ ] while the shimmering process was more than four times as fast $\left(\omega_{\mathrm{sh}}=\right.$ $101.45 \pm 1.48^{\circ}$ per $20 \mathrm{~ms}$ ) and, nonetheless, independent from the wasp's movement direction $\left(R^{2}=0.0422 ; P=0.2040\right.$, Pearson test; $\mathrm{n}_{\mathrm{ss}}=50$ sessions; $\mathrm{n}_{\mathrm{ff}}=6,891$ inter-frame intervals; Fig. 2e).

Coincidence in the movement directions of both parties ( $w$ and $s h$ ) can be particularly demonstrated if their alignment rates are viewed synchronously (Fig. 3). The rates of ipsi-directional alignment $\left(\mathrm{R}_{\mathrm{I}}=0.1920 \pm 0.0121\right.$, at $\Delta$ cat $\theta_{\mathrm{w}-}$ $\mathrm{sh}=[0])$ were significantly higher than those of contradirectional alignment $\left(\mathrm{R}_{\mathrm{C}}=0.1157 \pm 0.0050\right.$, at $\Delta$ cat $\theta_{\mathrm{w}-}$ $\mathrm{sh}=[-4] ; P<<0.001 ; t$ test). Similar results are achieved for the broader comparison, with the expansion of ipsi- and contra-directionality by combinations of angular sectors (see the logic schemes in Fig. 3 and Materials and methods). The positive factor $R_{I} / R_{C}$ under synchronous conditions (Fig. 3c) displays here the phenomenon of ipsi-directional dominance $\left(\mathrm{D}_{\mathrm{id}}\right)$ which was traced in singular sessions (e.g. Fig. 3 a; $\mathrm{n}_{\mathrm{ff}}=191$ ff. $P<0.001, \chi^{2}$ test) and proved for the entirety of sessions investigated $\left(\Delta \mathrm{R}_{\mathrm{I}-\mathrm{C}}>0: P<0.001, t\right.$ test; $\mathrm{n}_{\mathrm{ss}}=50$ sessions; $\mathrm{n}_{\mathrm{ff}}=6,891$ inter-frame intervals; Fig. 3b,c). Figure $4 \mathrm{a}$ shows the $\mathrm{D}_{\text {id }}$ histogram regarding dominance classes for the example of the wasp as responder $(s h \rightarrow w)$; it refers to synchronous assessment (lag=0) of all sessions $\left(\mathrm{n}_{\mathrm{ss}}=50\right)$ observed.
Ipsi- and contra-directional alignment of shimmering waves with the wasps' flight paths under time-shift conditions The streams of behaviours as documented in the Movies 1-10 result from the continuous interactions of both parties upon each other. We isolated the reactions of each party from the continuum of mutual signals $(w-s h-w-s h-\ldots)$ by utilizing the principle that any reaction happens after any stimulus but with delay. Fast flyers, such as wasps and bees, display latency periods not shorter than $20 \mathrm{~ms}$. Therefore, a time window of up to five frames ( $\equiv 100 \mathrm{~ms}$ ) will be sufficiently long to trace any responsiveness of each of the parties expressed by their motions. For the graphical summarization in Fig. $4 \mathrm{~b}$ and $\mathrm{c}$, the wasps' responses $(s h \rightarrow w)$ are displayed by positive time shifts (lag $[w$ after $s h]>0)$, and the responses of the bees $(w \rightarrow$ $s h)$ are displayed by negative time shifts (lag $[w$ after $s h]<0$ ). The results document ipsi-directional dominance $\left(\mathrm{D}_{\mathrm{id}}: \mathrm{R}_{\mathrm{I}}>\right.$ $\mathrm{R}_{\mathrm{C}}$ ) in both aspects of interactions under all time-shift conditions investigated $\left(P<0.001, \mathrm{t}\right.$ test; $\left.\mathrm{n}_{\mathrm{ss}}=50\right)$ whereas $\mathrm{D}_{\text {id }}$ decreased slightly but significantly with increasing absolute lags.

Asymmetry in ipsi-directional dominance We compared the values of $D_{\text {id }}[|\operatorname{lag}|>0]$ with those under synchronous assessment as reference (ref $\mathrm{D}=\mathrm{D}_{\mathrm{id}}[\mathrm{lag}=0]$ ), separately for every session $\left(\mathrm{n}_{\mathrm{ss}}=50\right)$ for wasps and shimmering bees. The differences of the $D_{\text {id }}$ values between both lag conditions $\left(\Delta \mathrm{D}_{\text {id }}=\mathrm{D}_{\text {id }}[|\operatorname{lag}|>0]-\right.$ ref $\left.\mathrm{D}\right)$ decreased with the absolute lag value (Fig. 5), but, which is important, differently strongly
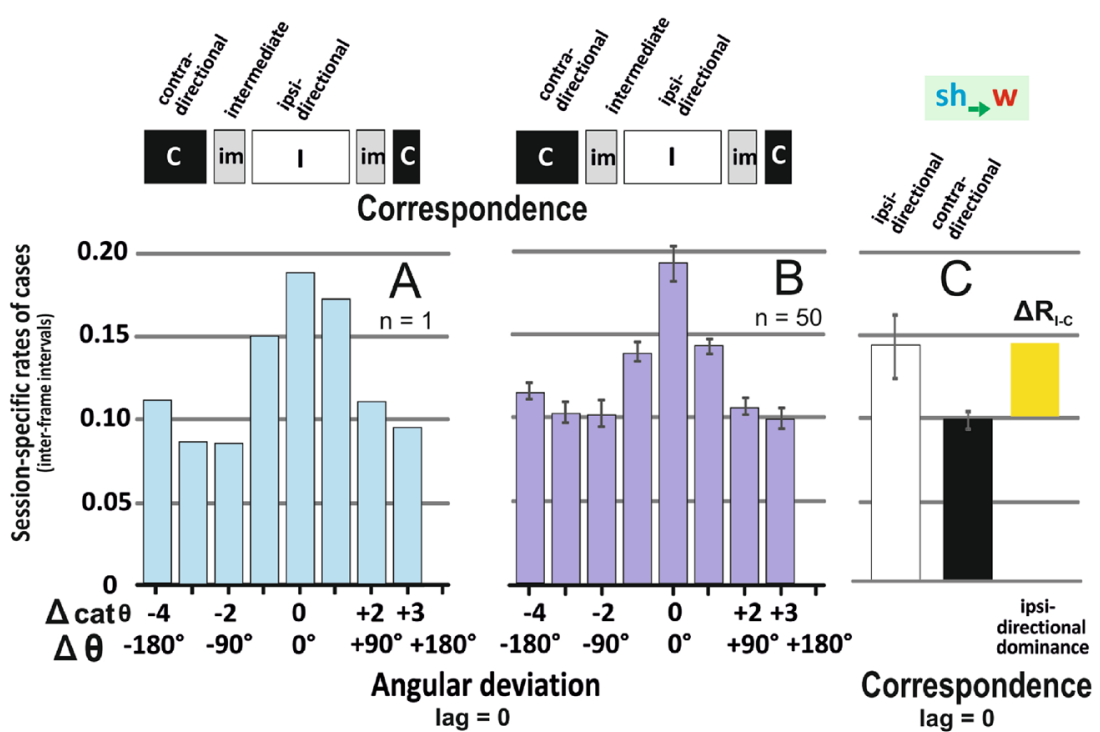

Fig. 3 Angular deviations between wasp and shimmering wave $(s h \rightarrow w$, lag $=0$ ). Session-specific rates of cases displaying angular deviation between wasp and shimmering. Abscissa, eight classes of angular deviation scaled in $\Delta$ cat $\theta$ and $\Delta \theta$ (for definition, see Figs. 1a, S2/Online Resource 2); ordinate, relative number of cases (=inter-frame intervals of $20 \mathrm{~ms}$ ) per angular deviation class; The value 1.0 refers to the total of cases per session. a The distribution of the rate of cases exemplified for the session 43 (blue columns). b Means (violet columns) and SEMs (grey

vertical bars) of all sessions $\left(\mathrm{n}_{\mathrm{ss}}=50\right)$. The graphs above the histograms define the angular sectors for ipsi-directional (code I; white colour code), intermediate (im; grey) and contra-directional (C; black) correspondence between the directions of the wasp's flight $(w)$ and of the movement of the gravity point of shimmering $(s h)$ per time step. $\mathbf{c}$ The difference between the session-specific mean rates ( $\mathrm{R}$ ) of ipsi-directional (white column) and contra-directional (black column) cases of alignment, termed as ipsidirectional dominance $\left(\mathrm{D}_{\mathrm{id}} \equiv \Delta \mathrm{R}_{\mathrm{I}-\mathrm{C}}\right.$; yellow column $)$ 

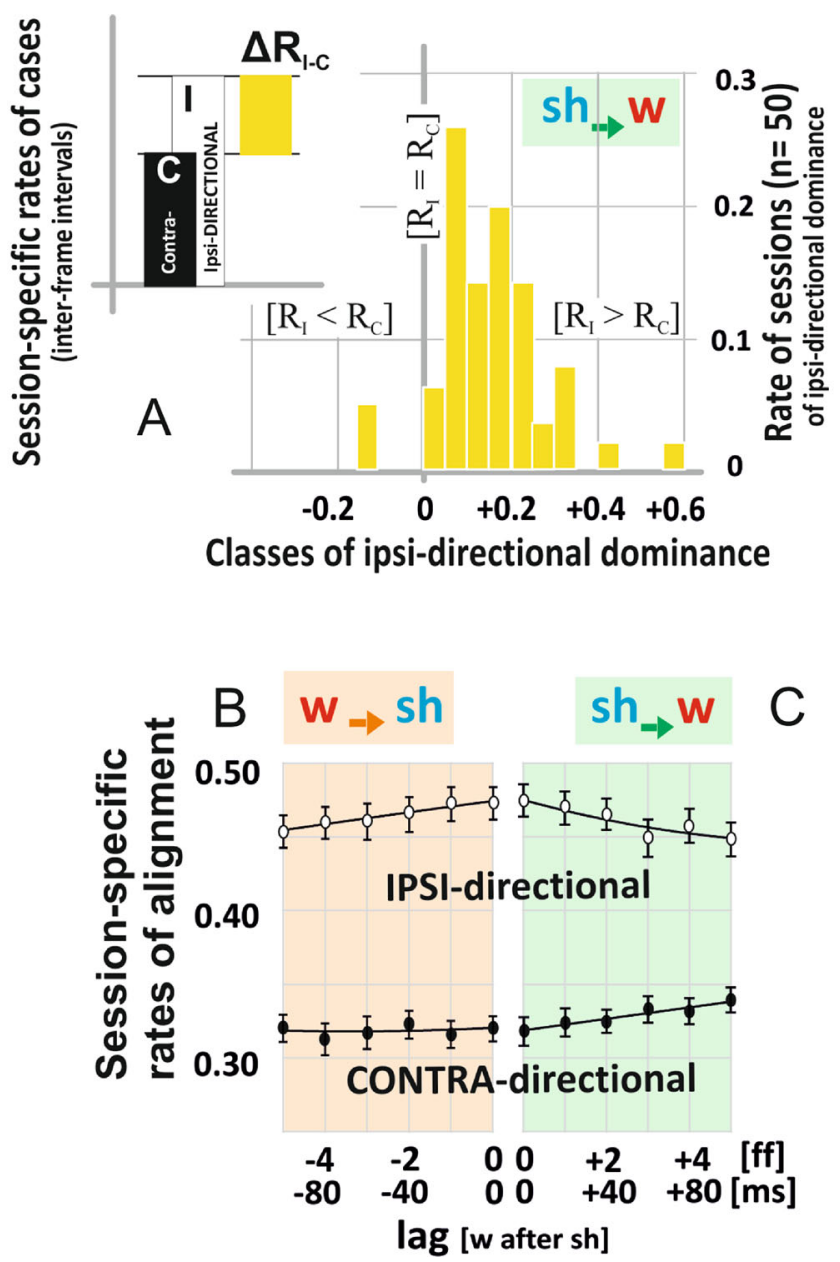

Fig. 4 Characteristics of alignment between wasps and honeybees $(w \rightarrow$ $s h, s h \rightarrow w)$. a Histogram of the cases of ipsi-directional dominance $\left(\mathrm{D}_{\mathrm{id}}\right.$, $\left.\mathrm{n}_{\mathrm{ss}}=50\right)$; abscissa, dominance classes of ipsi- (I) and contra- (C) directional alignment $\left(\Delta \mathrm{R}_{\mathrm{I}-\mathrm{C}} ; s h \rightarrow w\right.$; lag $\left.=0\right)$ with the definitions: class [0], equity conditions $\left[\mathrm{R}_{\mathrm{I}}=\mathrm{R}_{\mathrm{C}}\right]$; class $[+1],\left[\mathrm{R}_{\mathrm{I}}=1, \mathrm{R}_{\mathrm{C}}=0\right]$; class [-1], $\left[\mathrm{R}_{\mathrm{I}}=\right.$ $\left.0, R_{C}=1\right]$. Ordinate, rate of sessions of ipsi-directional dominance $D_{i d}$ (yellow). b-c Session-specific rates (ordinate) of alignment, under both modes of interaction $(s h \rightarrow w, w \rightarrow s h$ ), whereby the total of cases sums up to the value of 1.0 per session $\left(\Sigma R=R_{I}+R_{i m}+R_{C}=1\right)$; abscissas give the latency selected (lag $[s h \rightarrow w] \equiv \operatorname{lag}[w$ after $s h]$ ) in frames [ff] and milliseconds [ms]; data volume: $\mathrm{n}_{\mathrm{ff}}=6.891$ inter-frame intervals; $\mathrm{n}_{\mathrm{ss}}=50$ sessions

in the two aspects of interaction: for shimmering bees as responders $(w \rightarrow s h)$, the $\Delta \mathrm{D}_{\mathrm{id}}$ values differed slightly from the reference, whereas for wasps as responders $(s h \rightarrow w)$ the $\Delta D_{\text {id }}$ values decreased much stronger with increasing time shifts (Fig. 5a). Consequently, at longer time shifts ( $|\operatorname{lag}|>3)$ shimmering bees as responders had larger $\Delta \mathrm{D}_{\text {id }}$ values $(P=$ $0.0153, t$ test; Fig. 5a) and their rates $\mathrm{P}\left(\Delta \mathrm{D}_{\text {id }}\right)$ differed more strongly than with wasps as responders.

In a second independent analysis (Fig. S4/Online Resource 4 ), we counted the signs of the $\Delta D_{\text {id }}$ values of each session to classify two categories of ipsi-directional dominance (see sketch in Fig. S4A/Online Resource 4). For $\Delta D_{\text {id }}>0$, the alignment response exceeded the reference (ref D) displaying

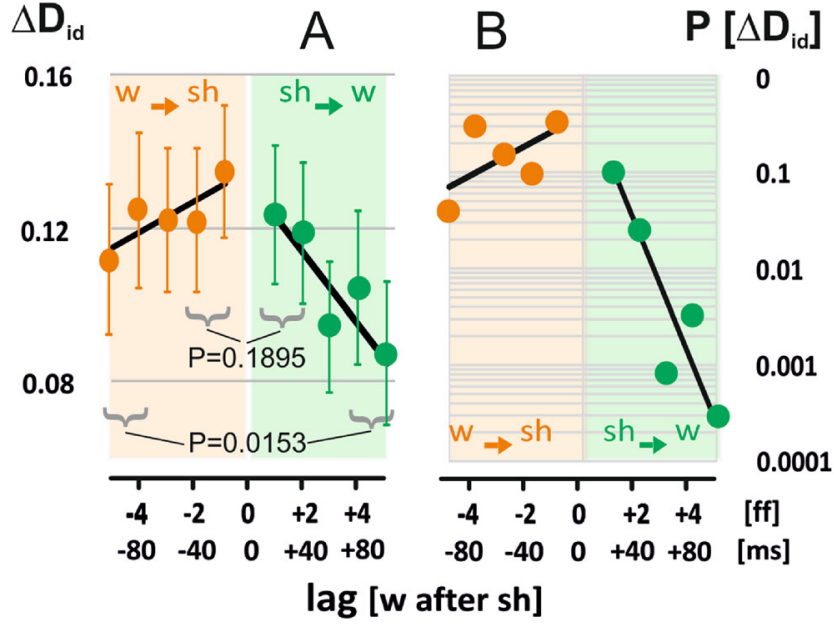

Fig. 5 Asymmetry of ipsi-directional dominance $\left(\mathrm{D}_{\mathrm{id}}\right)$ between wasp and shimmering $(w \rightarrow s h, s h \rightarrow w)$. a Session-specific differences in ipsidirectional dominance with the session-specific synchrony conditions as reference $\left(\Delta \mathrm{D}_{\mathrm{id}}=\left\{\Delta \mathrm{R}_{\mathrm{I}-\mathrm{C}}[|\mathrm{lag}|>0]-\right.\right.$ ref $\left.\mathrm{D}\right\}$ with ref $\mathrm{D}=\Delta \mathrm{R}_{\mathrm{I}-\mathrm{C}}[\mathrm{lag}=0]$; for further information, see Figs. 3-4). Asymmetry between both aspects (brown, $w \rightarrow$ sh; green, $s h \rightarrow w$ ) is proved at higher lags $(|\operatorname{lag}|=0-1$ : $P=0.1895 ;|\operatorname{lag}|=4-5: P=0.0153, t$ test; $\left.\mathrm{n}_{\mathrm{ss}}=50\right)$. Circles, means; vertical bars, SEMs. b Significance values ( $t$ test) of the differences of $D_{\text {id }}$ values $\left(\mathrm{n}_{\mathrm{ss}}=50\right)$ between lagged and synchronous conditions; ordinate $P$ $\left(\Delta \mathrm{D}_{\mathrm{id}}\right)=P\left\{\Delta \mathrm{R}_{\mathrm{I}-\mathrm{C}}[\mid\right.$ lag $\mid>0]$-ref $\left.\mathrm{D}\right\}$, in both aspects of interactions. Abscissa: lag [w after $s h]$ ) scaled in ff and ms (cf. Figs. 3-4)

the supra-reference status of ipsi-directional dominance (supra- $\mathrm{D}_{\mathrm{id}}$ ), whereas for $\Delta \mathrm{D}_{\mathrm{id}}<0$ the alignment response was classified as sub-reference status (sub- $\mathrm{D}_{\text {id }}$ ). The rates of supra$\mathrm{D}_{\text {id }}$ traits (Fig. S4B/Online Resource 4; $P=0.0135$, paired $t$ test; $\mathrm{n}_{\text {lag }}=5$ ) and the magnitudes of supra- $\mathrm{D}_{\text {id }}$ values at bigger latencies ( $\mid$ lag $\mid>2 ; P=0.0020, t$ test; $\mathrm{n}_{s h \rightarrow w}=49, \mathrm{n}_{w \rightarrow s h}=56$; Fig. S4C/Online Resource 4) were higher in shimmering bees as responders than in preying wasps as responders. Conversely, the magnitudes of sub- $\mathrm{D}_{\text {id }}$ rates (Fig. S4C/Online Resource 4) decreased with absolute latencies in both aspects of interaction.

Both findings (Figs. 5, S4/Online Resource 4) demonstrate that shimmering bees have the capacity to align their collective response with the wasp's flight direction significantly longer, at least up to $100 \mathrm{~ms}$, than the wasps are able to align their flight paths to the propagation direction of the shimmering waves. This is proved by the findings that the wasps significantly reduced both magnitude and rate of $\Delta \mathrm{D}_{\text {id }}$ (sh $\rightarrow$ w: Fig. 5) already $40 \mathrm{~ms}$ past the onset of the driving cue, whereas shimmering bees even increased the magnitude of supra- $\mathrm{D}_{\mathrm{id}}$ values at time shifts of $>40 \mathrm{~ms}$ $(w \rightarrow s h:|\operatorname{lag}|>2$; Fig. S4C/Online Resource 4).

Dependence of alignment of shimmering waves with preying wasps on topological relations A typical A. dorsata nest is shaped alike a hemispherical plate and measures mostly more than $1 \mathrm{~m}$ in the horizontal span. It also has specialized regions, most of them peripheral to the mouth region, where 
shimmering waves are generally initiated (Schmelzer and Kastberger 2009). A wasp usually preys around the bees' nest by hovering or scanning at an average distance of $50 \mathrm{~cm}$ (Kastberger et al. 2008), also below and above the nest, possibly by favouring certain regions of it. Therefore, it makes sense to include the relations between the positions of the wasp and of the gravity centres of the shimmering waves at every time step of interaction, from both perspectives $(w \rightarrow s h$ and $s h \rightarrow w)$. For that, four positional conditions were distinguished $\left(\mathrm{POS}_{1-4}\right.$ : Figs. $6 \mathrm{c}$ and $\left.7 \mathrm{c}\right)$ in which the positional centre of one party was at the right, left, top or bottom side of that of the other party.
The histograms (Figs. 6b and 7b) exemplify the aspect of shimmering bees and wasps as responders for the time shift of $20 \mathrm{~ms}(|\operatorname{lag}|=1)$. The alignment rates were sorted into four directional ( $\left.\mathrm{DIR}_{1-4}\right)$ and four positional $\left(\mathrm{POS}_{1-4}\right)$ classes while for each experimental session $\left(n_{\mathrm{ss}}=50\right)$ the total rate of interframe intervals was normalized as 1.0. The findings display preference of the wasps for specific positions at the nest, which probably results from site properties of the honeybee nest (and which would certainly differ with other nests). For the shimmering bees as responders ( $w \rightarrow s h$; Fig. 6b), most of the cases of alignment happened, irrespective of ipsi- or contra-directionality, at the positional relation $\operatorname{POS}_{1}(\equiv t r-b l)$,

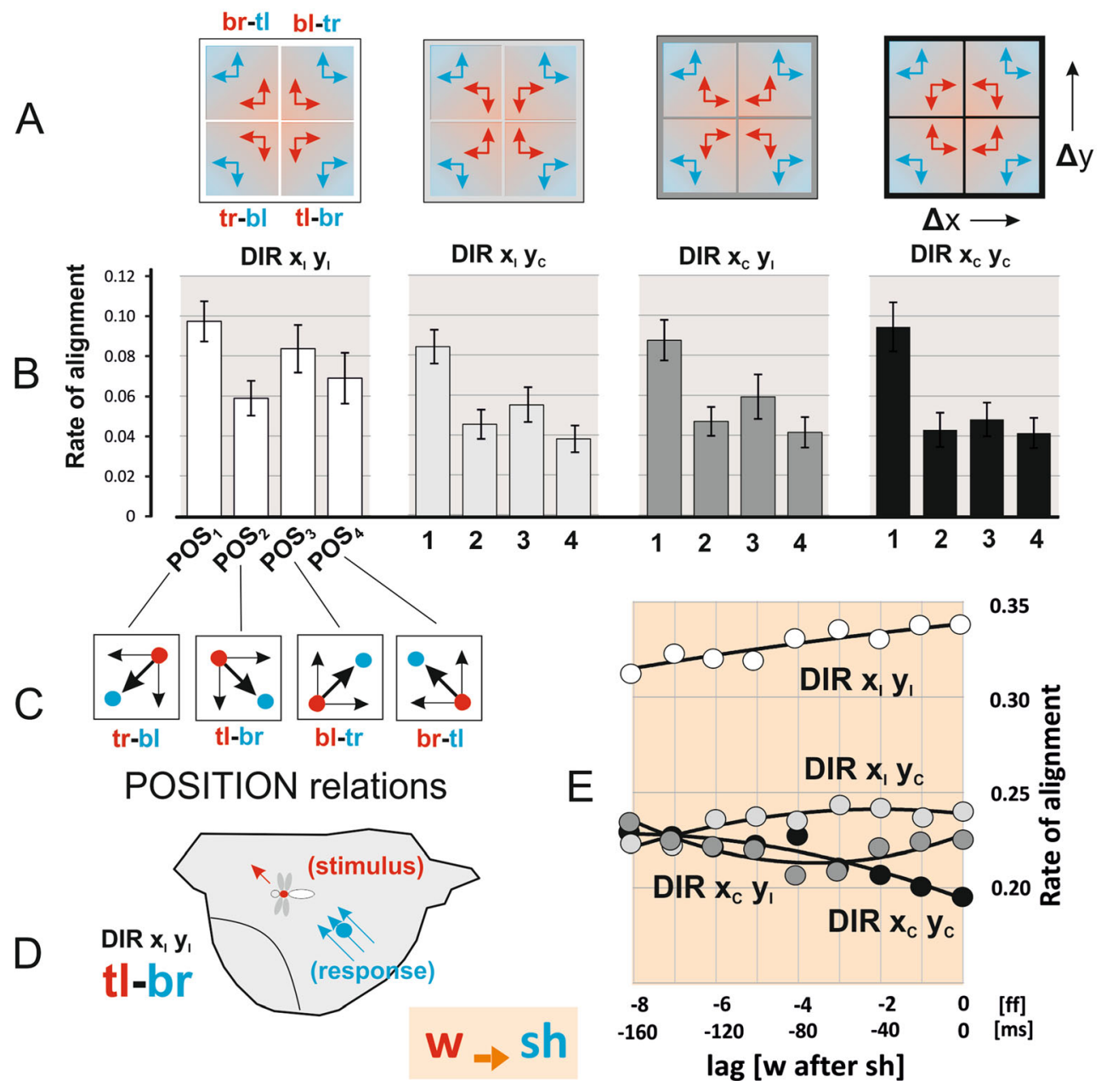

Fig. 6 Directional alignment $(w \rightarrow s h)$ as assessed with the split-component method. This approach distinguishes four directional conditions of the wasp (coded red) and the gravity centre of the shimmering wave (coded blue). a The sketches explain the pairs of positional deviations $(\Delta \mathrm{x}$ and $\Delta \mathrm{y})$ given for the four categories of alignments with ipsidirectional (code I) and contra-directional (code C) dispositions (as displayed in panel B). b Ordinate, alignment rates (DIR $\mathrm{x}_{\mathrm{I}}, \mathrm{y}_{\mathrm{I}}$, white bars in the histograms; DIR $\mathrm{x}_{\mathrm{I}}, \mathrm{y}_{\mathrm{C}}$, bright grey; DIR $\mathrm{x}_{\mathrm{C}}, \mathrm{y}_{\mathrm{I}}$, dark grey; DIR $\mathrm{x}_{\mathrm{C}}, \mathrm{y}_{\mathrm{C}}$, black) sorted after four positional relations (abscissa POS $_{1-4}$, see panel $C$ ) summed up to the rate value of 1.0 for each of the sessions investigated $\left(\mathrm{n}_{\mathrm{ss}}=50\right)$; Histogram bars, arithmetical means; vertical lines, SEMs; the empirical data were exemplified for latency conditions of lag=

1. c Four positional relations: $\mathrm{POS}_{1}$ : tr-bl; $\mathrm{POS}_{2}$ : tl-br; $\mathrm{POS}_{3}$ : bl-tr; $\mathrm{POS}_{4}$ : br-tl; with $t$ top; $r$ right; $b$ bottom; $l$ left). d The specific constellation tl-br, where the wasp as stimulus was positioned in the given frame at the topleft (red: $\mathrm{tl}$ ) of the gravity centre of the shimmering wave as responder. Conversely, the gravity centre of the shimmering wave was positioned at the bottom-right (blue: br) of the wasp. e Summarization of alignment rates regarding the four directional relations $\left(\mathrm{DIR}_{1-4}\right)$ : ordinate, the rate of alignment as defined in panel $\mathrm{B}$; circles, medians of alignment rates regarding $\mathrm{POS}_{1-4}$, normalized to 1.0. Abscissa, latency in frames [ff] and milliseconds [ms] between wasp flight as stimulus and shimmering wave as response; regression polynomials: DIR $\mathrm{x}_{\mathrm{I}} \mathrm{y}_{\mathrm{I}}, R^{2}=0.7927$; DIR $\mathrm{x}_{\mathrm{I}}$ $\mathrm{y}_{\mathrm{C}}, 0.8160 ;$ DIR $\mathrm{x}_{\mathrm{C}} \mathrm{y}_{\mathrm{I}}, 0.7577$; DIR $\mathrm{x}_{\mathrm{C}} \mathrm{y}_{\mathrm{C}}, 0.9187$ 
Fig. 7 Directional alignment (sh $\rightarrow w$ ) as assessed by the splitcomponent method. The sketch in panel D displays the sample constellation br-tl when the wasp positioned in the given frame at the top-left (red: $\mathrm{tl}$ ) of the gravity centre of the shimmering wave (blue: br) was considered as responding to the shimmering wave as stimulus. e Regression polynomials: DIR $\mathrm{x}_{\mathrm{I}} \mathrm{y}_{\mathrm{I}}, R^{2}=$ 0.8564; DIR $\mathrm{x}_{\mathrm{I}} \mathrm{y}_{\mathrm{C}}, 0.5698$; DIR $\mathrm{x}_{\mathrm{C}} \mathrm{y}_{\mathrm{I}}, 0.2323$; DIR $\mathrm{x}_{\mathrm{C}} \mathrm{y}_{\mathrm{C}}$, 0.3841 ). For further information, see Fig. 6

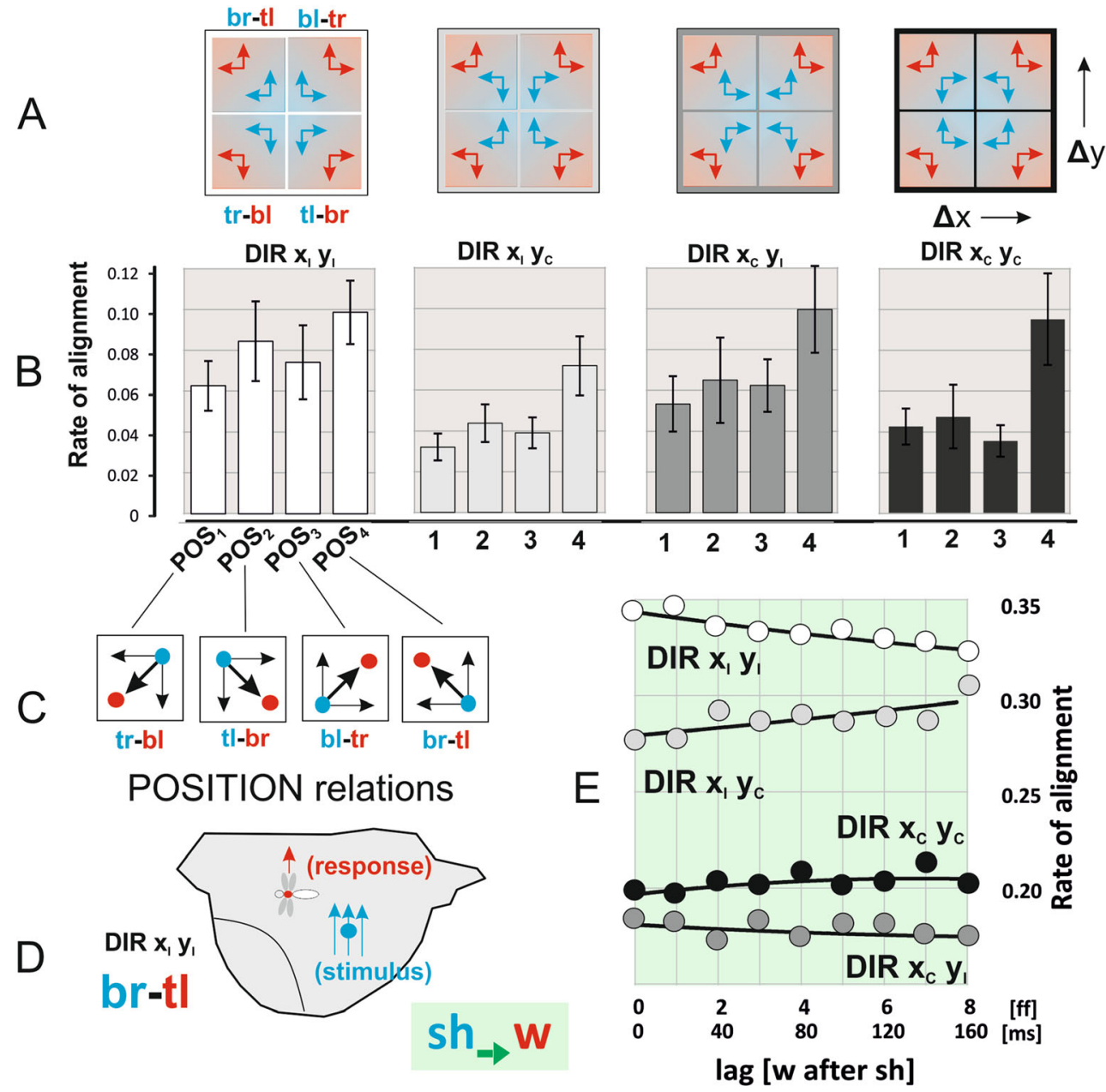

in which the wasp as stimulus was top-right (tr) to the gravity centre of the shimmering wave. Cross-referencing with the other aspect of interaction ( $s h \rightarrow w$; Fig. $7 b$ ) confirms that the positional preference of the wasp as responder was given at $\mathrm{POS}_{4}(\equiv b r-t l)$.

Directional preferences for alignment The defence hypothesis of shimmering has been proved for the aspect that shimmering waves have the potential to repel threatening wasps away from the nest (Kastberger et al. 2008). If directional alignment of shimmering waves with the wasp's flight favours this repelling ability, shimmering waves should "follow" the wasp with the same diligence in any direction on the vertical plane of the nest surface (see Movies 1-10). With other words, the bees should not prefer in their alignment ability any flight direction of the wasp. Conversely, it can be expected that the wasp is neither benefitted by the direction of shimmering nor by her own alignment reaction to shimmering waves. Therefore, the wasp could likely be influenced in her responsiveness by secondary features such as site attributes of the bees' nest (as actually demonstrated in the Figs. $6 b$ and $7 b$ ).
Using the split-component method (see Material and methods), the attendances for directional alignment of shimmering bees and wasps in their roles as responders to the other party's signals ( $s h \rightarrow w, w \rightarrow s h$ ) were distinguished into four DIR $_{1-4}$ classes (Figs. 6e and 7e). Both parties mainly align ipsi-directionally $\left(\mathrm{DIR} \mathrm{x}_{\mathrm{I}} \mathrm{y}_{\mathrm{I}}\right)$ whereby the rates decreased with increasing latency periods. The bees as responders $(w \rightarrow s h)$ aligned at a lower level (Fig. 6e) under partial and full contradirectionality $\left(\mathrm{DIR} \mathrm{x}_{\mathrm{C}} \mathrm{y}_{\mathrm{I}}, \mathrm{DIR} \mathrm{x}_{\mathrm{I}} \mathrm{y}_{\mathrm{C}}, \mathrm{DIR} \mathrm{x}_{\mathrm{C}} \mathrm{y}_{\mathrm{C}}\right.$ ). This gives evidence that the bees responded to all flight directions of the wasp with the same strength of alignment, conforming to the predictions of the defence hypothesis of shimmering. Conversely, the wasps as responders $(s h \rightarrow w)$ were more prone to horizontal than to vertical alignment with shimmering. This is displayed by the DIR $\mathrm{x}_{\mathrm{I}} \mathrm{y}_{\mathrm{C}}$ graph in Fig. 7e which is positioned between proper ipsi-directionality (DIR $\mathrm{x}_{\mathrm{I}} \mathrm{y}_{\mathrm{I}}$ ) and $\mathrm{x}$ based contra-directionality (DIR $\left.\mathrm{x}_{\mathrm{C}} \mathrm{y}_{\mathrm{I}}, \mathrm{DIR} \mathrm{x}_{\mathrm{C}} \mathrm{y}_{\mathrm{C}}\right)$.

Estimation of the empirical headings We compared the casespecific proportions of alignment values ( $\mathrm{r}\left[\mathrm{DIR}_{1-4}\right]$, see Figs. 6 and 7) with those of the mathematical heading model (Fig. S3/Online Resource 3) according to the best-match 
$\left(\max -\chi^{2}\right)$ criterion. In the simplest assumption that both parties $(w$ and $s h)$ equal in the headings $\left(\mathrm{h}_{\mathrm{x}, \mathrm{y}}[s h]=\mathrm{h}_{\mathrm{x}, \mathrm{y}}[w]\right)$ the best match will result at a heading of $h=0.34$ (coded by green colour in Fig. S3A,B,E/Online Resource 3).

For the best match with the empirical data, the two pairs of headings $\left(\mathrm{h}_{\mathrm{x}, \mathrm{y}}[s h], \mathrm{h}_{\mathrm{x}, \mathrm{y}}[w]\right)$ were permutated stepwise. Figure S3D/Online Resource 3 illustrates here the last step of such a search for a selected proportion of headings $\left(\mathrm{h}_{\mathrm{x}}[\mathrm{w}]=\right.$ $0.59, \mathrm{~h}_{\mathrm{y}}[\mathrm{w}]=0.67, \mathrm{~h}_{\mathrm{x}}[\mathrm{sh}]=0.62$ ), for which the missing vertical heading component was determined at the maximum of the respective regression polynomial $\mathrm{P}\left[\chi^{2}\right]=\mathrm{f}\left(\mathrm{h}_{\mathrm{y}}[\mathrm{sh}]\right)$ with $h_{y}[s h]=+0.154$. Otherwise, the best-match permutation for the equity conditions of all partial headings $\left(\mathrm{h}_{\mathrm{x}}[s h]=\mathrm{h}_{\mathrm{y}}[s h] ; \mathrm{h}_{\mathrm{x}}\right.$ $\left.[w]=\mathrm{h}_{\mathrm{y}}[w]\right)$ can be assessed according to the look-up table of Fig.S3/Online Resource 3 (green arrows). That way, multiple runs of the model led to the determination of the heading components of the empirical wasp's flights with $h_{x}[w]=$ 0.18 and $\mathrm{h}_{\mathrm{y}}[w]=0.34$ and of the associated shimmering waves with $\mathrm{h}_{\mathrm{x}}[s h]=0.24$ and $\mathrm{h}_{\mathrm{y}}[s h]=0.16$.

These findings show that the wasp slightly emphasized the vertical heading whereas the shimmering responses were more uniform herein. Interestingly, they also may explain the conundrum of the ipsi-directional dominance $\left(\mathrm{D}_{\mathrm{id}}\right)$ in alignment under synchronous assessment conditions (Figs. 3 and $4 \mathrm{~b}, \mathrm{c}$ ) because such alignment conditions (displayed by the green histograms in Fig. S3B/Online Resource 3, in comparison with the histograms in Figs. $6 \mathrm{~b}$ and $7 \mathrm{~b}$ ) differed significantly from the random-walk process. Therefore, it is plausible to assume that the phenomenon of ipsi-directional dominance does result from an alternative process, most likely from the interference of the continuous, mutual and asymmetric interactions of the parties, which themselves switch repetitively between signaller and responder roles.

\section{Discussion}

The multiple goals of defence of shimmering The wave-like shimmering in giant honeybees (Seeley et al. 1982; Oldroyd and Wongsiri 2006; Woyke et al. 2006; Kastberger et al. 2012, $2013 \mathrm{a}, \mathrm{b}$ ) is a collective action of the bees on the nest surface with the potential to repel predatory wasps (e.g. the autochthon species of Vespa orientalis, V. tropica, Vespa mandarinia). Such wasps usually hover or scan in front of the bees' nest, preying on the stationary curtain bees or ambushing homing or departing forager bees in flight (Kastberger et al. 2008, 2011a). It is important to note here that the interactions between shimmering bees and preying wasps occur exclusively in the visual domain and that the repelling impact of shimmering is connected only with its flash-like rise in the ascending phase of the shimmering process (when the synchronously active cohort of bees increases in size within the period of $200-300 \mathrm{~ms}$; see Kastberger et al. 2008, 2013b). This kind of visual flash elicits an avoidance response in the wasp addressee, making it fly away from the bees' nest. However, as soon as the synchronously or serially shimmering-active cohort became smaller, at about $300 \mathrm{~ms}$ after the onset of the wave, the wasp resumes her preying activity (Kastberger et al. 2008).

Shimmering behaviour, however, provides additional features to dispel wasps from the range of the bees' nest. If the wasp comes nearer to the nest or if she increases her flight speed in passing by the nest, the repetition rate of the shimmering waves is increased (Kastberger et al. 2008). If the threatening wasp eventually touches the nest, small local waves are produced which efficiently confuse the wasp and hamper its further effort to prey directly from the nest surface (Kastberger et al. 2008). If, nevertheless, a wasp is still in the touching position with the nest to capture a bee from the nest surface, curtain bees immediately draw her into the nest heatballing her to death (Kastberger and Stachl 2003; Kastberger et al. 2011b) alike in other Apis species (Apis cerana: Ono et al. 1987, 1995; Ken et al. 2005; Apis mellifera; Tan et al. 2007; Apis florea; Seeley et al. 1982). All these facets of collective defence make it practically impossible for a wasp to concentrate on distinct spots and to capture a bee directly from the surface of a giant honeybee nest.

In this paper, a further defence goal of shimmering has been addressed, which may be counted among the most sophisticated traits in collective defence in insects (Johnstone 1997; Smith and Harper 2003; Alcock 2005). It is the specific ability of shimmering-active surface bees to couple the direction of their collectively produced wave with the momentary direction of the flight path of a threatening wasp (Movies 110). Importantly, this alignment behaviour initiated by the bees makes the wasp in turn follow the shimmering wave. This capacity of the shimmering-active surface bees seems to be an example of predator driving (termed as the mobbing analogue of prey driving; see Coppinger 2001; Hayward et al. 2011), which is documented in context with mobbing behaviour in vertebrates (Curio 1978; Dominey 1983; Arnold 2000; Osthreiher 2003). Mobbing behaviours have been reported from individuals of species of potential prey (Curio 1978; Alcock 2005), that cooperatively attack or harass unwanted intruders (cf. Chevalier 2013), usually to protect their offspring or to drive them away from a food source. In particular in birds, mobbing behaviour includes a series of displays such as flying about, dive bombing, loud squawking, defecating on the intruder and even summoning nearby individuals to cooperate in the attack by producing mobbing calls (Leger and Carroll 1981; Alcock 2005).

The findings in A. dorsata (Kastberger et al. 2008 and this paper), however, leave it still unclear whether shimmering in honeybees conforms to any of the latter mobbing theories. What is known up to now is that shimmering giant honeybees, 
as potential prey, is not likely to warn the intruders away from the nest by signalling physical fitness (which, however, has been proposed for the homologous behaviour in A. cerana; Tan et al. 2012). We see strong evidence that the flash-like shimmering patterns actually force the preying wasp to escape. The bees utilize particularly here startle reactions of the wasp as response to the ascending recruitment of shimmering participants in the first $300 \mathrm{~ms}$ of a wave (Kastberger et al. 2008, 2013b). But in a second defence line, shimmering also provides the phenomenon of directional alignment between the honeybees as prey and wasps as predators, which can be well compared to defence actions such as an African buffalo herd's when confronting a lion, of lining up and attacking it (Alcock 2005; Chevalier 2013). The behaviours in both scenarios (shimmering bees vs. wasp and buffalo herd vs. lion) have at least the same consequence that the counterparts, the counter-attacking prey and the retreating predator, move in ipsi-directional formation (except when the mobbed lion predator refuses, to its disadvantage, to do so; e.g. Chevalier 2013).

The questions which were asked in this paper are first, whether such ipsi-directional alignment behaviours of giant honeybees at the nest surface with the flight path of preying wasps do have the power to drive the wasp out of the range of the bees' nest, and second, whether the repelling capacity of shimmering flashes (Kastberger et al. 2008) is enhanced by this alignment behaviour. The data bring evidence for these surmises and document asymmetry in the mutual alignment responses of both counterparts (Fig. 5, S4/Online Resource 4) which benefits the bees to the disadvantage of the wasps. The findings support the directed-shimmering-drives-wasps hypothesis which expands upon the more general defence hypothesis of shimmering (Kastberger et al. 2008).

Mechanisms behind directional alignment Theoretically, if two parties move, each of them in random direction, correspondence of their headings is incidental (Fig. S3A-C/Online Resource 3). The opposite situation arises if significant portions of the moving paths of both parties are aligned, which may happen also independent from heading values. Basically, moving organisms may align themselves in their headings of their motions in a large variety of displays. In the simplest way, directional alignment is caused by vectored structures of the ambient milieu, such as acoustic or gravitation gradients, or a stream current which, for example, makes a trumpet fish swarm swaying back and forth with the wave action of the water (Kuiter 2001). A more self-determined way of individuals to align their posture or movement directions is observed when the presence of others triggers the heading of an entire group of specimens. This happens in fishes in schooling (Reynolds 1987) or in swimming together with larger specimens such as pilot fishes following sharks (Randall et al. 1997); it happens in bird flocks (e.g. Ballerini et al. 2008), in the alignment on pheromone trails (Wilson 1962; Dorigo et al.
2000) and, which is important here, also in the interaction between potential predators and their prey (Alcock 2005; Chevalier 2013). These latter forms of directional alignment are caused by interactions between usually moving agents which show reactive interventions, mutual signalling and individual decisions.

In this paper, we utilized the latency aspect to separate the driving cues from the driven responses in the alignment reactions. This method bases on the principle that any reaction or any decision produced upon a driving signal occurs with a typical delay after the onset of the respective stimulus. In a prey-predator interaction, however, this principle is more complex because both parties have a double role; they emit signals and also respond to stimuli of the counterpart while one of the goals, defence or predation, finally happen to dominate.

Asymmetries between the directional alignments of the interacting counterparts One of the covert principles behind directional correspondence, which has also been addressed in this paper, is the symmetry of its origin. Directional correspondence is evoked symmetrically if both counterparts align with similar strength and is evoked asymmetrically if only one of the two interacting counterparts has the ability to react, to decide and to align, or if one party dominates this kind of interaction. Theoretically, if neither the preying wasp nor the shimmering bees shows any tendency to mutual alignment, both counterparts would deliver a uniform distribution of their movement or posture directions in the entire circular range of $360^{\circ}$. The findings (Fig. 3), however, give evidence that directional alignment between shimmering bees and preying wasps is quite a dominant factor, and if the movements of both parties ( $w$ and $s h$ ) are compared in a stimulus-response paradigm by considering latencies, also asymmetries between the alignment responses of shimmering bees and wasps were traced (Fig. 5). By comparing the empirical data with the movement heading model (Fig. S3/Online Resource 3), it becomes clear that the phenomenon of ipsi-directional dominance (Figs. 3, 4, 5 and 6) can be seen as a form of steady-state alignment resulting from the continuous and directional interactions between prey and predator.

It is a matter of course that any alignment response between predators and their prey should be asymmetric due to the intrinsic difference of their goals. For the bees, as potential prey, any directional alignment will have more importance in benefitting the colony if the goal of alignment is to enhance the repellence power of shimmering (Kastberger et al. 2008). On the other side, wasps may recognize shimmering waves as a "nasty" visual cue to be "ignored" at the earliest possible moment. It is unlikely that any signal emitted by shimmering would benefit the wasps (cf. Kastberger et al. 2008), such as to prevent them from wasting time trying unsuccessfully to catch bees from the nest surface (which otherwise would be 
predicted by the handicap principle, Zahavi 1997). The findings brought up at least three aspects of asymmetry behind the alignment responses of shimmering bees and preying wasps, and, importantly, all of them are potentially benefitting the collective of honeybees.

Three aspects of asymmetry First, following roughly parallel courses, both counterparts were quite different in their turning velocities (Fig. 4e). When turning, shimmering waves were, independently of the heading of the wasps, more than four times as fast as the wasps; this makes shimmering bees to be more reactive than wasps on prey.

Second, the findings (Figs. 4-7; see also Movies 1-10/ Online Resources 5-14) show that both counterparts may be aligned to each other at a level of up to $15 \%$, but with significant differences shimmering bees aligned their collective response with the wasp's flight continuously for at least $100 \mathrm{~ms}$ (Figs. 5, S4/Online Resource 4) after the onset of the signals produced by the wasps' flight manoeuvres. The motive force of the wasp for active alignment was here much lower, as it decreased substantially already $40 \mathrm{~ms}$ after the respective signal from the shimmering pattern (Fig. 5). These findings designate the shimmering bees as the more persisting and thus dominating part in the mutual alignment process.

Third, the bees aligned their shimmering waves with the same strength in all directions (Fig. 6e), with no directional preference with the flight path of the wasps. This means that the bees recognize the wasp as a threat independently of the direction of her flight path. The wasps, however, were more reactive to horizontal than vertical movements of shimmering (Fig. 7e). Their alignment reactions are obviously influenced by the topology of the bees' nest site. This preference for horizontal structures can be seen as a form of ideomotor responses (which are otherwise known of being associated with psychological contexts in humans rather than with insect behaviours; see Carpenter 1852; Stock and Stock 2004).

In summary, the capacity for continuous directional alignment of the shimmering waves with the flight path of wasps enhances the repelling power of shimmering (Kastberger et al. 2008). The honeybees, as compared to predatory wasps, take at least a threefold advantage of an asymmetry in the preypredator interaction: by a higher turning velocity of their moving patterns (Fig. 2e), by a greater persistence (Figs. 5, S4/Online Resource 4) and by a uniform directionality (Figs. 6e and 7e). These findings may support the surmise that directional alignment of shimmering giant honeybees towards a wasp on prey make up the phenomenon of predator driving. This phenomenon is generally associated with mobbing behaviour, such as in selfish herds of vertebrate species (Hamilton 1971; Curio 1978; Arnold 2000; Alcock 2005; Chevalier 2013), but is, until now, unknown in the insect world (cf. Tan et al. 2012).
Acknowledgments We thank Dr. Madhu Singh, Dr. S.M. Man, Dr. R. Thapa and Dr. M. B. Gewali from Tribhuvan University, Kathmandu, Nepal, for their support regarding logistics.

Funding The study has been supported by the Austrian Science Fund (FWF Project P 20515-B16). The funders had no role in study design, data collection and analysis, decision to publish, or preparation of the manuscript.

Ethics statement The government office of the Tribhuvan University (Centre for International Relations) of Kathmandu (Nepal) certified the research expedition under the title "Study on the behaviour of the giant honeybees: observations and recording of behaviours at the nesting site in the Chitwan district of Nepal 2009 and 2010".

Open Access This article is distributed under the terms of the Creative Commons Attribution License which permits any use, distribution, and reproduction in any medium, provided the original author(s) and the source are credited.

\section{References}

Alcock J (2005) Animal behavior, 8th edn. Sinauer Associates Inc, Massachusetts

Arnold KE (2000) Group mobbing behaviour and nest defence in a cooperatively breeding Australian bird. Ethology 106:385-393. doi:10.1046/j.1439-0310.2000.00545.x

Ballerini M, Cabibbo N, Candelier R, Cavagna A, Cisbani E, Giardina I, Lecomte V, Orlandi A, Parisi G, Procaccini A, Viale M, Zdravkovic $\mathrm{V}$ (2008) Interaction ruling animal collective behavior depends on topological rather than metric distance: Evidence from a field study. PNAS 105:1232-1237

Carpenter WB (1852) On the Influence of Suggestion in Modifying and directing Muscular Movement, independently of Volition. Proc R Inst Great Brit:147-153 www.sgipt.org/medppp/psymot/carp1852. htm. Accessed 23 July 2014

Chevalier N (2013) Cape buffalo kills a Lion - Jun 14, 2013. www. youtube.com/watch?v=PJjcQBSPDaI. Accessed 23 July 2014

Coppinger R (2001) Dogs. A new understanding of canine origin, behavior and evolution. University of Chicago Press, Chicago

Curio E (1978) The adaptive significance of avian mobbing: I. Teleonomic hypotheses and predictions. Z Tierpsychol 48: $175-183$

Dominey WJ (1983) Mobbing in colonially nesting fishes, especially the Bluegill, Lepomis macrochirus. Copeia 4:1086-1088

Dorigo M, Bonabeau E, Theraulaz G (2000) Ant algorithms and stigmergy. Futur Gener Comp Syst 16(9):851-871

Einstein A (1926) Investigations on the theory of Brownian Movement. In: Fürth R (ed) Einstein, Collected Papers 2 (reprinted 1956), Dover Publications, New York, pp 170-182

Hamilton WD (1971) Geometry for the selfish herd. J Theor Biol 31(2): 295-311. doi:10.1016/0022-5193(71)90189-5

Hayward MW, Hayward GJ, Tambling CJ, Kerley GIH (2011) Do lions Panthera leo actively select prey or do prey preferences simply reflect chance responses via evolutionary adaptations to optimal foraging? PLoS One 6(9):e23607. doi:10.1371/journal.pone. 0023607

Johnstone RA (1997) The evolution of animal signals. In: Krebs JR, Davies NB (eds) Behavioural ecology: an evolutionary approach, 4th edn. Blackwell, Oxford, pp 155-178

Kastberger G, Stachl R (2003) Infrared imaging technology and biological applications. Behav Res Methods Instrum Comput 35(3):429-439 
Kastberger G, Schmelzer E, Kranner I (2008) Social waves in giant honeybees repel hornets. PLoS One 3(9):e3141. doi:10.1371/ journal.pone.0003141

Kastberger G, Weihmann F, Hoetzl T (2010) Complex social waves of giant honeybees provoked by a dummy wasp support the specialagent hypothesis. Commun Integr Biol 3(2):179-180

Kastberger G, Weihmann F, Hötzl T (2011a) Self-assembly processes in honeybees: the phenomenon of shimmering. In: Hepburn HR, Radloff SE (eds) Honeybees of Asia. Springer, Berlin, pp 397444. doi:10.1007/978-3-642-16422-4 1

Kastberger G, Maurer M, Weihmann F, Ruether M, Hötzl T, Kranner I, Bischof H (2011b) Stereoscopic motion analysis in densely packed clusters: 3D analysis of the shimmering behaviour in Giant honeybees. Front Zool 8:3, www.frontiersinzoology.com/content/8/1/3. Accessed 23 July 2014

Kastberger G, Weihmann F, Hötzl T, Weiss SE, Maurer M (2012) How to join a wave: Decision-making processes in shimmering behavior of giant honeybees (Apis dorsata). PLoS One 7(5):e36736. doi:10. 1371/journal.pone.0036736

Kastberger G, Weihmann F, Hoetzl T (2013a) Social waves in giant honeybees (Apis dorsata) elicit nest vibrations. Naturwissenschaften 100(7):595-609. doi:10.1007/s00114-013-1056-Z

Kastberger G, Hötzl T, Kranner I, Weiss SE, Maurer M, Weihmann F (2013b) Speeding up social waves. Propagation mechanisms of shimmering in giant honeybees. PLoS One 9(1):e86315

Ken T, Hepburn HR, Radloff SE, Yusheng Y, Yiqiu L, Danyin Z, Neumann P (2005) Heat-balling wasps by honeybees. Naturwissenschaften 92(10):492-495. doi:10.1007/s00114-005-0026-5

Kuiter RH (2001) Seepferdchen, Seenadeln, Fetzenfische und ihre Verwandten. Ulmer, Stuttgart

Leger DW, Carroll L (1981) Mobbing Calls of the Phainopepla. Condor 83(4):377-380. doi:10.2307/1367509

Oldroyd BP, Wongsiri S (2006) Asian honey bees. Harvard University Press, Cambridge

Ono M, Okada I, Sasaki M (1987) Heat production by balling in the Japanese honeybee, Apis cerana japonica as a defensive behavior against the hornet, Vespa simillima xanthoptera (Hymenoptera: Vespidae). Experientia 43:1031-1032
Ono M, Igarashi T, Ohno E, Sasaki M (1995) Unusual thermal defence by a honeybee against mass attack by hornets. Nature 377:334-336

Osthreiher R (2003) Is mobbing altruistic or selfish behaviour? Anim Behav 66:145-149

Randall JE, Allen GR, Steene RC (1997) Fishes of the great barrier reef and coral sea. Crawford House Press, Bathurst

Reynolds CW (1987) Flocks, herds and schools: a distributed behavioral model. Comput Graph 21(4):25-34. doi:10.1145/37401.37406

Schmelzer E, Kastberger G (2009) 'Special agents' trigger social waves in giant honeybees (Apis dorsata). Naturwissenschaften 96(12): 1431-1441. doi:10.1007/s00114-009-0605-y

Seeley TD, Seeley RH, Akratanakul P (1982) Colony defence strategies of the honeybees in Thailand. Ecol Monogr 52:43-63

Smith MJ, Harper D (2003) Animal signals. Oxford University Press, Oxford

Stock A, Stock C (2004) A short history of ideo-motor action. Psychol Res 68:176-188

Tan K, Radloff SE, Li JJ, Hepburn HR, Yang MX, Zhang LJ, Neumann P (2007) Bee-hawking by the wasp, Vespa velutina, on the honeybees Apis cerana and A. mellifera. Naturwissenschaften 94(6):469-472

Tan K, Wang Z, Li H, Yang S, Hu Z, Kastberger G, Oldroyd BP (2012) An 'I see you' prey-predator signal between the Asian honeybee, Apis cerana, and the hornet, Vespa velutina. Anim Behav 83(4): 879-882

Waddoup D (2014) Homeothermy in giant honeybees (Apis dorsata): occurrence of convection funnels. Master Thesis, Graz

Weihmann F, Hötzl T, Kastberger G (2012) Training for defence? From stochastic traits to synchrony in Giant honeybees (Apis dorsata). Insects 3(3):789-820. doi:10.3390/insects3030789

Wilson EO (1962) Chemical communication among workers of the fire ant Solenopsis saevissima (Fr. Smith): 3. The experimental induction of social responses. Anim Behav 10:159164

Woyke J, Wilde J, Wilde M, Cervancia C (2006) Abdomen flipping of Apis dorsata breviligula worker bees correlated with temperature of nest curtain surface. Apidologie 37:501-505

Zahavi A (1997) The handicap principle: a missing piece of Darwin's puzzle. Oxford University Press, Oxford 